Z. Klin. Chem. Klin. Biochem.

11. Jg. 1973 , S. $270-272$

\title{
IR-Nachweis von Serumproteinen auf Cellulose-Acetat Vereinfachter Weg zur Auswertung ungefärbter Cellulose-Acetat-Folien-Elektropherogramme
}

\author{
Von M. Wenzed und Katharina Hoffmann
}

Biol. Chem. Abteilung ain Pbarmazeutischen Institut der Freien Universität Berlin, Berlin-Dablem.

(Eingegangen am 13. April/11. Mai 1973)

\author{
Herrn Professor Dr. Dr. Ernst Scbütte qum 65. Geburtstag genvidmet
}

Das Absorptionsmaximum von Proteinen im Infrarot-Licht bei $6 \mu \mathrm{m}$ entspricht dem Absorptionsminimum von Cellulose-Acetat. Es las Streuung im Infrarot im Vergleich zu sichtbaren Licht ist es nicht nötig, die Folie transparent zu machen. Es ist somit prinzipiell möglich, die Auswertung von Serum-Elektropherogrammen auf Cellulose-Acetat-Folie erheblich zu vereinfachen.

\section{Tie detection of serum proteins on cellulose acetate with IR. A simplified method for the evaluation of unstained electro- i) pherograms on cellulose acetate membranes}

Protein has a strong IR-absorption near $6 \mu \mathrm{m}$, while the absorption of cellulose acetate at this wavelength is minimal. Therefore $10-300 \mu \mathrm{g}$ of protein can be measured on cellulose-acetate without staining and without the problem of light-scattering. It is possible to apply this principle to the evaluation of clinical serum-electropherograms.

Die elektrophoretische Auftrennung von Serumproteinen auf Cellulose-Acetat-Folie ist eine Standardmethode im klinisch-chemischen Laboratorium. Zur photometrischen Bestimmung der getrennten Proteinfraktionen wird das Protein auf der Cellulose-AcetatFolie angefärbt und anschließend der Farbüberschuß eluiert. Außerdem muß die Folie noch durch geeignete Verfahren transparent gemacht werden, da die unbehandelte Folie den Meßstrahl zu stark streut. Erst nach dieser relativ langwierigen Behandlung des Elektropherogramms kann dann die Photometrie beginnen. $\mathrm{Da}$ die Lichtstreuung im IR-Bereich im Vergleich zu sichtbarem Licht erheblich getinger ist, untersuchten wir Möglichkeiten zur Elektropherogramm-Auswertung im Infrarot-Licht. Es sollte dabei eine für die Praxis relevante Frage beantwortet werden: Gibt es Wege, die bisher übliche Prozedur der Auswertung zu vereinfachen?

\section{Ergebnisse und Diskussion}

Absorptions-Spektren von Cellulose-Acetat und Serumeiweiß im IR-Bereich

Eine Voraussetzung für die Protein-Bestimmung auf Cellulose-Acetat mit Infrarot-Licht ist das unterschiedliche Absorptions-Spektrum von Protein und Trägerfolie. Wir untersuchten daher die IR-Absorption des Trägermaterials Celullose-Acetat und von Serum-Albumin. In beiden Fällen wurden die Materialien mittels der Kaliumbromid-Technik analysiert. Abbildung 1. zeigt die entsprechenden Absorptionskurven für die Wellenlängen von $2,5-7,7 \mu \mathrm{m}$ entsprechend einer Wellenzahl

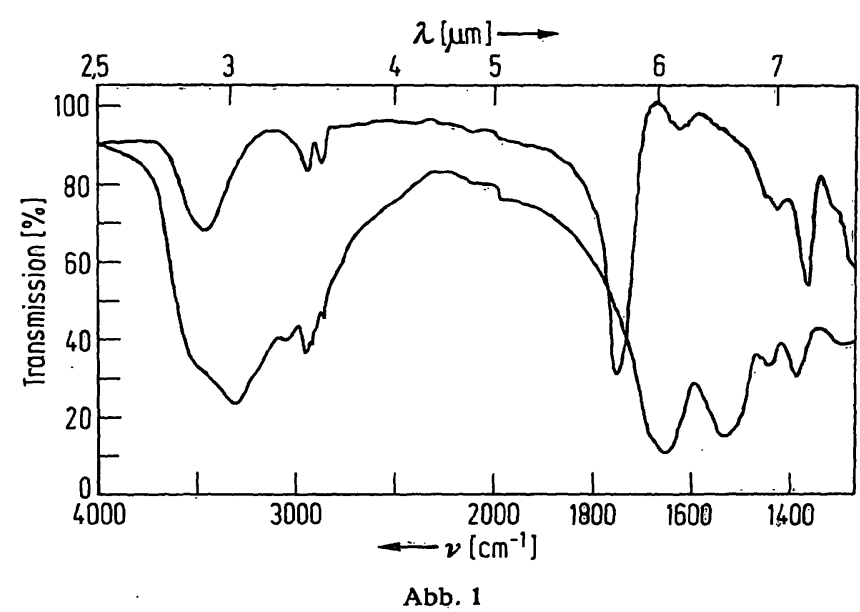

IR-Absorptionsspektren von Cellulose-Acetat und Human-Albumin Obere Kurve: Cellulose-Acetat $1 \mathrm{mg} / 400 \mathrm{mg} \mathrm{KBr}$ Untere Kurve: Human-Albumin $2 \mathrm{mg} / 400 \mathrm{mg} \mathrm{KBr}$

Die Cellulose-Acetat-Folie wurde klein geschnitten und die Schnipsei in einer Kugelmühle zu feinem Pulver zermahlen. Ein abgewogener Anteil des Pulvers wurde mit Kaliumbromid $(\mathrm{KBr})$ vermischt und anschließend in üblicher Weise zu einer Pille gepreBt

von $4000-1300 \mathrm{~cm}^{-1}$. Die Zuordnung der verschiedenen Absorptionsbanden zu den verschiedenen charakteristischen Atomgruppen und Schwingungstypen soll hier nicht im einzelnen diskutiert werden. Dies ist ausführlich an anderer Stelle geschehen (1). Entsprechend unserer Problem-Stellung interessiert nur die relative Lage der Absorptions-Maxima bzw. - Minima des Trằgermaterials einerseits und des Proteins andererseits. Man erkennt aus dem Absorptions-Spektrum von Albumin (untere Kurve in Abb. 1), daß das Protein die stärkste Absorption bei $1650 \mathrm{~cm}^{-1}$ aufweist. Dies entspricht 
einer $\mathrm{C}=\mathrm{O}$-Valenzschwingung, die bei allen Amiden auftritt (Amidbande I) (2). Außerdem erkennt man die Amidbande II bei $1530 \mathrm{~cm}^{-1}$, die einer NH-Deformations-Schwingung entspricht. Demgegenüber zeigt das Spektrum von Cellulose-Acetat (Abb. 1 obere Kurve) gerade in diesem Bereich die geringste Absorption. Das Minimum der Eigenabsorption der Trägerfolie bei $1670 \mathrm{~cm}^{-1}$ bietet eine gute Voraussetzung für die IRphotometrische Bestimmung von Proteinen auf Cellulose-Acetat.

Die in Abbildung 1 gezeigten Absorptions-Verhältnisse für Cellulose-Acetat (als $\mathrm{Pulver}$ in $\mathrm{KBr}$ ) waren identisch mit den Spektren, die mit Cellulose-Acetat-Folie aufgenommen wurden. Der größeren Schichtdicke und der stärkeren Streuung im kurzwelligen IR-Bereich wegen konnte jedoch eine Registricrung nur bei Wellenlängen größer als $5 \mu \mathrm{m}\left(2000 \mathrm{~cm}^{-1}\right)$ vorgenommen werden.

\section{Serumeineiß-Bestimmung auf Cellulose-Acetat-Folie}

Als nächstes untersuchten wir die Beziehung zwischen Proteinmenge und Extinktion bei $1650 \mathrm{~cm}^{-1}$ auf Cellulose-Acetat-Folie. Dazu wurden Albumin-Lösungen bekannter Konzentrationen mit Hilfe einer Hamilton-Spritze auf vorher in Phosphat-Puffer getränkte Cellulose-Acetat-Folie strichförmig aufgetragen. Damit von dem IR-Strahl das gesamte Protein eines Flecks erfaßt wurde, war das von der Protein-Lösung bedeckte Areal stets kleiner als die Fläche des beleuchteten $\mathrm{Meß}$ spaltes. Abbildung 2 gibt die Beziehung zwischen gemessener Extinktion und aufgetragener Probenmenge wieder. Danach erhält man eine lineare Eichkurve im Bereich von 10-300 $\mu \mathrm{g}$ Protein. Eine lineare Beziehung erhielt man ebenfalls bei IR-Messung der Proteinmenge nach erfolgter Elektrophorese von reinem Albumin.

Nach unseren Untersuchungen eignet sich nicht nur die in Abbildung 2 gewählte Amidbande I, sondern ebenfalls die Amidbande II als Meß-Wellenlänge. Dagegen erwiesen sich die im Bereich der NH-Valenzschwin-

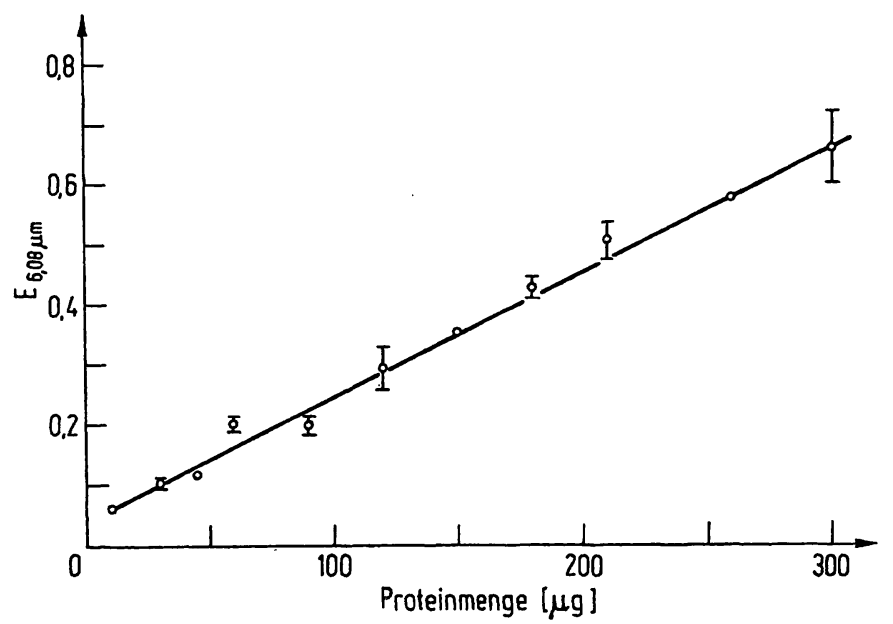

Abb. 2

Abhängigkeit der Extinktion $(\lambda=6,08 \mu \mathrm{m})$ von der Protein-Menge auf

Cellulose-Acetat-Folie
Steigende Mengen von Albumin (gelöst in Phosphat-Puffer pH 7,3) wurden mit einer Hamilton-Spritze auf einzelne Cellulose-AcetatBlättchen aufgetragen. Nach dem Trocknen wurden die Blättchen mi einer Hilfsvorrichtung vor den Meßspalt des IR-Spektrographen gesetz und die Absorption im Vergleich zu Protein-freien Blättchen gemessen $\vec{x} \pm 6(n=4)$ gungen gemessenen Werte $\left(\mathrm{um} 3000-3500 \mathrm{~cm}^{-1}\right)$ weniger geeignet. Dies liegt wahrscheinlich an der zu geringen Durchlässigkeit von Cellulose-Acetat in diesem Bereich, die durch die starke Lichtstreuung bei diesen kurzen Wellenlängen bedingt ist. Wir verwendeten daher für alle weiteren Messungen die Amidbande I als Meß-Wellenlänge.

Obwohl innerhalb einer Konzentrationsreihe die Liniarität zwischen Extinktion und Proteinmenge recht gut war, ergaben sich öfter merkliche Abweichungen zwischen verschicdenen Eichkurven bei Eiweißmengen $>150 \mu \mathrm{g}$.

Vcrmutungen, daß diese Schwankungen durch unterschiedliche Schichtdicke oder Trocknung der Trägerfolie bedingt sind, konnten nicht bestätigt werden. Auch das Drehen und Wenden der Folie im Meßstrahl (Uberprüfen örtlicher unterschiedlicher Oberflächenbeschaffenheit der Folie) und eine Gegenüberstellung von Puffer-getränkten und -ungetränkten Folien ergaben keine bemerkenswerte Differenz. $\mathrm{Zu}$ den Abweichungen bei höheren Protein-Konzentrationen führen möglicherweise beim Auftragen nicht zu vermeidende Unregelmäßigkeiten, $z$. B. unterschiedliche Größe der Substanz-Flecken, Herausragen der Flecken aus dem Meßspalt oder unglciche mengenmäßige Verteilung innerhalb des Fleckens eine Rolle.

Nach unseren Untersuchungen ist also der quantitative Nachweis von ungefärbten Proteinen im Bereich von $10-300 \mu \mathrm{g}$ auf Cellulose-Acetat-Folie durch IR-Licht bei $1650-1680 \mathrm{~cm}^{-1}$ bzw. $6 \mu \mathrm{m}$ möglich. $\mathrm{Da}$ in diesem Wellenlängen-Bereich alle Serumproteine ihr Absorptionsmaximum haben, ist prinzipiell die quantitative Auswertung von Serum-Elektropherogrammen auf Cellulose-Acetat-Folie möglich. Wir haben daher versucht, ungefärbte und nicht transparent gemachte Elektropherogramme von Human-Serum auf CelluloseAcetat-Folie nach dem hier beschriebenen Prinzip auszuwerten.

Abbildung 3 zeigt ein entsprechendes Beispiel mit vermehrtem $\beta$-Globulin-Gehalt, wie durch die übliche Anfärbemethode bestätigt werden konnte. Das Verfahren gibt also die Möglichkeit, die Auswertung von Elektropherogrammen auf Cellulose-Acetat-Folie gegen-

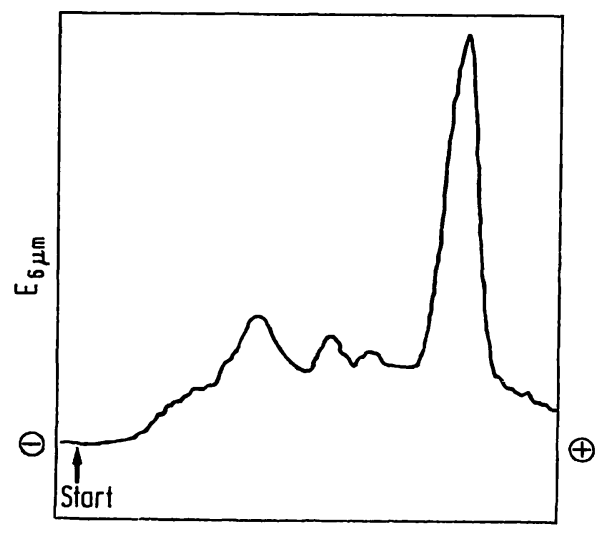

Abb. 3

Photometrische Auswertung eines ungefärbten Serum-Elektrophero-

gramms auf Cellulose-Acetat-Folie
Nach der Elektrophorese von $2 \mu$ Serum (mit $\beta$-Globulin-Vermelirung) auf Cellulose-Acetat in Phosphat-Puffer ( $\mathrm{pH} 8,2)$ wurde die Folie getrocknet und unverändert durch IR-Licht bei $6,08 \mu \mathrm{m}$ ausgemessen. Im Vergleiclisstrall befand sich eine Protein-freie Cellulose-AcetatFolie. Während der Messung wurde das Elektropherogramm durch ein Getriebe mit konstanter Geschwindigkeit am Spalt vorbei transportiert (Originalkurve mit Ordinatenspreizung) 
über den bisher üblichen Methoden erheblich zu vereinfachen. Außerdem vermeidet diese Methode Fehler, die durch unterschiedliche Anfärbbarkeit von Albumin und Globulin auftreten, da die IR-Absorption nur durch die Anzahl der Peptidbindungen bedingt ist (3). Es ịst das Ziel gegenwärtiger Untersuchungen, das hier aufgezeigte Prinzip für die tägliche Praxis verwertbar zu machen (4).

\section{Materialien und Geräte}

Die als Trägermaterial dienende Cellulose-Acetat-Folie wurde von der Sartorius-Membranfilter $\mathrm{GmbH} / \mathrm{Göttingen} \mathrm{bezogen}$ (Katalog Nr. 11200, Format $25 \times 160$ ).
Als Proteinproben wurden verwendet:

1. Serum-Albumin vom Rind, trocken, reinst bezogen von den Behringwerken/Marburg.

2. Protein-Lösung (Nr. 3) aus der „Biochemica Test Combination, Gesamteiweiß Farb-Test" der Fa. Boehringet/Mannheim.

3. Humanserum.

Alle Messungen wurden an dem IR-Hochleistungsgerät 225 und dem dazugehörendem Zweitschreibersystem der Fa. PerkinElmer Uberlingen/Bodensee ausgeführtt. Fụ̈ die Auswertung von Elektropherogrammen wurden diese in den Transportschlitten eines Getriebes eingesetzt und damit bei konstanter Geschwindigkeit $(5 \mathrm{~cm} / \mathrm{min})$ am Meßspalt vorbeigeführt. Das Signal wurde durch das Zweitschreiber-System in eine der Extinktion proportionale Größe transformiert und in Abhängigkeit vom Vorschub des Elektropherogramms dargestellt.

\section{Literatur}

1. BeLlAMY, L. J. \& BRÜGEL, W. (1966), „Ultrarot-Spektrum und chemische Konstitution", 2. Auflage, D. Steinkopf Verlag, Darmstadt. - 2. RübNer, H. \& Albers, P. (1967), J. Chromatog.
27, 510. - 3. Korn, J. (1971), Glas. u. Instrumenten-Technik (GIT) 11, 1221-1229. - 4. WenZEL, M. (1.973) J. Chromatogr. im Druck.
Prof. Dr. M. Wenzel

1 Berlin 33 (Dahlem)

Königin-Luise Str. 2-4 